\title{
PROCESOS COGNITIVOS Y CRÍTICA POLÍTICA: ¿UNA POLÍTICA ILUSTRADA EN SENTIDO PLATÓNICO?
}

\author{
Josep MONSERRAT MOLAS \\ Departament de Filosofia Teorètica i Pràctica \\ Facultat de Filosofia \\ Universitat de Barcelona \\ jmonserrat@ub.edu
}

RESUMEN: La tensión entre una concepción oligárquica y una concepción democrática de la política corre pareja a la tensión entre una concepción elitista y otra universalista del conocimiento. Hasta qué punto el texto platónico del Político sostiene ambos extremos de las dos tensiones es algo que también se relaciona con la complejidad de la metáfora náutica que gobierna el argumento político.

PALABRAS CLAVE: conocimiento, sistema sociocultural, ilustración, política, platonismo

SUMMARY: The tension between an oligarchical and a democratic conception of politics is parallel to the tension between an elitist or a universalist conception of knowledge. Both poles of both tensions are, in the platonic text Statesman, related to the complexity of the nautical metaphor that governs the political argument.

KEY WORDS: knowledge, socio-cultural system, enlightenment, politics, Platonism

\section{Introducción}

La metáfora que compara el gobierno de una ciudad con el manejo de una nave es una de las más comunes para caracterizar el ámbito de lo político, como lo son también la asimilación de la figura del gobernante con el pastor o la de la ciudad toda con un cuerpo orgánico (Briguglia 2006). No pretendo ahora desarrollar esta cuestión, sino simplemente fijarme en cómo la imagen correlativa puede contener una virtualidad que iría más allá de su propio desarrollo. Así, para entrar en la cuestión que nos atañe debe notarse - siguiendo a Edwin Hutchins, quien ha estudiado minuciosamente las operaciones cognitivas de la tripulación de un barco - que la inteligencia no radica solamente en las computaciones individuales: la misma tripulación, entendida como un todo en la navegación, opera como un sistema sociocultural de computación que aprende colectivamente en la tarea común de enfrentarse a rutinas. La cultura no se entiende aquí como una colección de cosas, sino como un proceso cognitivo, y la cognición, por su parte, se entiende como un proceso cultural. Hutchins hace la siguiente observación: 
cuando los símbolos se encuentran en el ambiente de lo humano, y lo humano los manipula, las propiedades cognitivas de lo humano no son las mismas que las propiedades del sistema que es construido por lo humano en interacción con estos símbolos. Las propiedades de lo humano en interacción con los símbolos producen algún tipo de computación. Pero esto no significa que la computación suceda dentro de la cabeza de nadie. (Hutchins 1995, pp. 354, 361)

Es desde esta perspectiva del conocimiento en común desde donde se podría y debería pensar una ilustración o cultura política.

Que la argumentación que se presenta en los textos platónicos contra la viabilidad de la forma democrática de la política se sostenga sobre el prejuicio aristocrático según el cual el pueblo o dêmos no puede ser educado, pues el saber o la ciencia son sólo patrimonio posible de una minoría capaz y entregada a su cultivo, o bien que ese prejuicio no sea tal sino una conclusión argumental, debería matizarse atendiendo a las razones que se pueden encontrar en los textos platónicos respecto de las formas participativas del logro de la verdad, es decir, de las formas dialógicas y racionales de la investigación filosófica. De hecho, el principio restrictivo aristocratizante que conduciría en último término a la singularidad del filósofo-rey, que no es sino una difracción de la limitación constitutiva de la capacidad cognoscitiva humana, está matizado continuamente por el principio de necesidad de búsqueda comunitaria de la verdad. La lectura de los mismos argumentos platónicos atendiendo sobre todo a la constatación de tal "limitación constitutiva" y a la necesidad de una comunidad de saber que se realiza a través de la tarea educativa permitiría pensar las condiciones de algo así como una ilustración que podría ser compatible con diferentes formas de gobierno, entre ellas la democracia, atendiendo a la posibilidad de que, en Platón, la filosofía se entienda, sobre todo, como búsqueda de la sabiduría más que como sabiduría conseguida e, incluso, cuando se trata de conocimiento aprehendido, de qué tipo de sabiduría se trata. Con estos parámetros debe reflexionarse sobre la discutida relación de Platón con la democracia (Rowe 2001, p. 75; cfr. Mas 2009).

Si bien puede considerarse que Platón efectúa "una gran operación histórica por la que transforma la destrucción de hecho de la democracia en caducidad de derecho [...], porque era un régimen viciado en su fundamento, un régimen dominado por la multitud ignorante, la multitud apasionada y pasional y no por el sabio o la sabiduría, el justo o la injusticia" (Castoriadis 2003, p. 19), Castoriadis plantea, más allá de su crítica al absolutismo platónico, una 
consecuencia paradójica: "la consecuencia del texto platónico es evidente: la autoinstitución democrática permanente de la sociedad", porque "hay que educar a la gente de manera tal que pueda cerrar constantemente por sí misma la brecha entre los grámmata, las letras muertas de la ley, y la realidad" (Castoriadis 2003, p. 176). Resulta de este modo que la autonomía individual y colectiva está dada por la distancia esencial que existe entre las leyes escritas y la realidad. Esto permitiría que las leyes fueran reformuladas y que en realidad la actividad legislativa constituyera una actividad permanente. De ahí concluye que las potencialidades del texto de Platón, a pesar de sus intenciones, conducen a esta "autoinstitución permanente de la sociedad", cuyos sujetos activos serían la totalidad de los ciudadanos, el démos. Pensar esta figura posible en el texto platónico es el objetivo de estas páginas, pues, desde un punto de vista institucional, Platón también ha llegado a considerarse como un "crítico interno" de la democracia (Mas 2009, p. 193; Saxonhause 2006): no la rechazaría totalmente sino que apuntaría a un perfeccionamiento mezclándola con elementos propios de otros órdenes de dominación.

\section{Saber y opinión verdadera}

El pasaje bien conocido de Teeteto $201 a-c^{1}$ es suficiente para tratar la identificación del saber como opinión verdadera. Aquí, en efecto, Sócrates alude a la figura del juez, como contraejemplo o como prueba de la acusación, para desmentir tal identificación. El argumento aducido es el siguiente: el juez dicta sentencia sobre unos hechos de los que no tiene conocimiento directo, de forma que su juicio, cuando es recto (y debe serlo para poder merecer el nombre de juez) no lo es por constituir saber, sino por consistir en una recta opinión: hay, así pues, opinión verdadera sin conocimiento. Xavier IbáñezPuig ha hecho notar en su monografía sobre este diálogo que, en verdad, la remisión al tribunal de justicia en este pasaje es algo más que un contraejemplo, y aduce pruebas a favor de la tesis según la cual la figura del tribunal de justicia propone, por decirlo así, un modelo que salve aquello que de positivo tenían las metáforas del bloque de cera y la de la jaula de pájaros por separado, sin caer, empero, en los defectos que cada una de estas figuras tenía también por separado. Sugiere Ibáñez-Puig, pues, la posibilidad de pensar el tribunal de justicia como la tercera figura en la serie "bloque de cera

${ }^{1}$ Para las referencias a textos clásicos se sigue la práctica común de dar el autor, el título de la obra y la referencia a capítulos y apartados, con objeto de permitir al lector acudir a cualquier edición crítica. 
- jaula - tribunal", y, precisamente, como aquella figura que ofrece una mejor explicitación del conocimiento en la medida en que salva los aspectos receptivo (bloque de cera) y activo (jaula) del saber en una sola visión integrada del conjunto. Aunque, obviamente, una "figura del pensamiento" no es todavía una definición, en todo caso, lo que se esperaría en el tramo final del Teeteto es que aquel que conoce sea caracterizado no como un mero juez, sino como una cierta clase de juez (que es, en efecto, aquello que pasa con la propuesta de que quien conoce es aquel que juzga rectamente por mediación del lógos; Ibáñez-Puig 2007, 2011).

Sería posible, entonces, considerar esta figura del juez-tribunal desde una perspectiva democrática en contraposición a la perspectiva monárquica u oligárquica. La imagen platónica del juez-tribunal debe entenderse en su contexto y esto implica la posibilidad de una lectura más amplia que la restricción de la figura considerada a su acepción singular e individual. Así, en la letra "platónica" podemos contraponer, por ejemplo, la figura de Radamantis o de Minos en el Minos, como ejemplos del juez singular, con las apreciaciones que Sócrates pronuncia ante los "verdaderos jueces" al final de Apología, por ejemplo. Una "comunidad de saber" como la requerida constantemente en y por los diálogos platónicos estaría más próxima a la deliberación de un tribunal, del dikastérion, que a la mera decisión de un juez sabio (Abad y Monserrat 2009). En todo caso, su bondad dependería de la posibilidad misma de educar a los susceptibles de formar parte de la deliberación del tribunal. Pero antes conviene introducir una distinción para evitar ciertas distorsiones comunes en la recepción del pensamiento platónico.

\section{La transmisión de la Carta VII}

La cuestión de la transmisión de la experiencia filosófica se confunde a menudo con la cuestión de la transmisión del saber. Confundir las dos cosas lleva a profundos malentendidos. No es otra cosa una de las claves argumentales de la Carta VII. No sé si se ha atendido lo suficiente al sentido de la totalidad del texto de esta carta cuando uno se pregunta sobre el juego mismo que encierra como texto literario: la cuestión que se debate es la relación (de transmisión-educación) entre Platón/Dión, Dión/Dionisio, Platón/Dionisio, Dionisio/libro escrito, Dión/amigos y familiares de Dión, Platón/seguidores y familiares de Dión. Todas estas relaciones aparecen en el texto, y la última es el mismo texto. Atender a su éxito o su fracaso (o a su éxito y fracaso relativos) proporciona la trama argumental: si la cadena de 
transmisión "filosófica" funciona o no (Garrigasait 2009). No es ahora el momento de entrar en detalle al respecto, pero para lo que nos interesa quisiera sólo considerar el hecho singular de que Platón se dirija, en primera persona, y exponiendo posiciones fundamentales de su pensamiento, aquellas consignables por escrito, a unos "familiares y seguidores de Dión", la capacidad "filosófica" de los cuales no queda en ningún momento probada. Tal posibilidad de "educación" o "transmisión filosófica", que una comprensión no esotérica de los diálogos permitiría, y que se vería reforzada por la noticia de la "lección sobre el Bien" que Platón pronunció ante un público, o, incluso, por la posibilidad de que la carta verdaderamente enviada a los familiares y seguidores de Dión fuese la octava, y la séptima fuese algo así como una "carta abierta" al pueblo ateniense para defenderse de las acusaciones de amigo o adulador de los tiranos (de Dionisio, en concreto, dionysokólakes, para Epicuro; Diógenes Laercio $10.8=\mathrm{fr}$. 238 Usener = fr. 101,18 Arrighetti), no deja de ser, como decimos, la posibilidad de una figura del pensamiento.

\section{Valoración popular y fundamentación de la constitución}

En el Político de Platón, el Extranjero de Elea plantea la opinión según la cual si alguien sabe de leyes, tal individuo debe mandar, pero pregunta al joven Sócrates si sabe qué piensan los muchos, la gente, sobre esto. El joven no lo sabe. Los muchos afirman que si alguien sabe de leyes superiores deberá legislar según éstas, convenciendo antes a la ciudad. El joven parece que se contradice con lo que ha dicho anteriormente $(295 b, 296 a)$, cuando había aceptado la subordinación de la ley al político científico (Miller 1980, p. 30). Accattino (1997, p. 177, n. 50) reporta en extenso el procedimiento que se seguía en Atenas para cambiar una ley que debía pasar por el trámite necesario del convencimiento. ${ }^{2}$ Esta necesidad de convencer (peíthein) a la ciudad antes de imponer una ley es el requisito de los

${ }^{2}$ El procedimiento que se seguía en Atenas para cambiar una ley puede rastrearse en los testimonios de Demóstenes, Contra Timócrates 20 ss. y Esquines, Contra Ctesifonte 38-39. La iniciativa de proponer una ley podía provenir de la Asamblea o de un ciudadano o de los Tesmotetas (colegio de los seis arcontes, diferentes del arconte epónimo, del polemarco y del arconte rey, que tenían el encargo de fijar la ley, cfr. Aristóteles, Constitución de Atenas 3, 59). La nueva ley siempre se veía como una corrección de una ley existente y por eso la Asamblea designaba cinco abogados defensores de la ley vigente. Reunidos los colegios de los mil y un nomotetas, se procedía en la forma de un juicio en el que quien proponía la nueva ley actuaba de acusador y los abogados asumían la defensa de la ley antigua. Después del debate se votaba a mano alzada. 
muchos y, de hecho, la prueba de su poder, que se contrapone a la competencia técnica de los pocos (293a ss.). Fijémonos en que esto "suena bien" al Extranjero, y que el joven no lo encuentra correcto, pues prefiere que si alguien conoce la ley superior la imponga sin necesidad del asentimiento de los muchos.

Es por esta posibilidad de la imposición por donde avanza el diálogo; ahora bien, recordemos antes, como otros comentaristas, que este texto parece una autocitación de Platón, en concreto, del Critón (Critón 51b-c, 52a; cfr. Leyes 772c, 832c). En este diálogo, Sócrates encarcelado considera frente Critón qué dirían las leyes de la ciudad: "¿Y qué es necesario o bien convencerla [a la ciudad], o bien acatar lo que manda y sufrir con calma si determina sufrir [...] y doquier hacer lo que manda la ciudad y la patria, o convencerla de manera que se avenga con la justicia?" El argumento está destinado a conjurar la preocupación de Critón hacia la opinión de la mayoría de la gente, ya que Sócrates no la tiene en consideración: "¿Pero qué nos importa, excelente Critón, la opinión de la gente? Los mejores, en cuyo parecer vale más preocuparse, creerán que las cosas han pasado como han pasado realmente."

La respuesta del joven Sócrates en el Político (“¿Qué dices? ¿No es esto lo correcto?") muestra su acuerdo con la concesión final del Extranjero ("si no es así, no tengo que hacerlo"), lo que quiere decir que si no es necesario convencer a la ciudad, no tiene que hacerlo. El joven Sócrates, frente a la disyuntiva del Extranjero (convencer o no a "los muchos") se muestra a favor de la opinión oligárquica aristocratizante, a saber, no es necesario convencerlos. Se entiende, entonces, que el Extranjero introduzca una duda: ¿qué pasa cuando no se puede convencer y se impone lo mejor? Lo que está suponiendo el Extranjero es el abandono de la condición del convencimiento - y por lo tanto del apoyo - de la ciudad (entiéndase, de los muchos o de la mayoría). En el tema de la persuasión, cabe pensar en la necesidad de haber retenido algo del arte de los sofistas, precisamente aquellos de los cuales se debe depurar la figura del político que se busca en la conversación. Antes de permitir que responda el joven, le recuerda el ejemplo del médico: ¿puede considerarse un mal médico aquel que imponga los remedios contra la voluntad del paciente? Parece que no puede considerarse que cometa falta alguna contra su arte (no es tan claro si no cometería una falta ética de un tipo diferente de los problemas técnicos; cfr. Rosen 1995). Por analogía pasa lo mismo con el legislador: los que se ven forzados a hacer algo más justo, mejor y más bello que aquello que hasta ahora era tradicional, si se quejan, quedan en ridículo y no pueden decir que 
hayan sido sometidos a una falta contra la justicia, una falta que, si lo fuera, sería, dice el Extranjero, vergonzosa, malvada e injusta ( $c f r$. Gorgias, $521 d-522 b$ ). El joven responde a las dos argumentaciones del mismo modo ("alethéstata legéis").

El de Elea recapitula, aquí, recordando que el legislador no debería estar sometido tampoco a discriminación por su riqueza o por la escritura de las leyes o por el convencimiento. Surge entonces la imagen que se convertirá en clásica, la que compara la política con la navegación:

Extranjero: [...] Así como el piloto, procurando siempre el provecho de la nave y de los navegantes, sin establecer normas escritas, sino haciendo de su arte ley, preserva la vida de quienes con él navegan, así también, del mismo modo, de quienes tienen la capacidad de ejercer de esta manera el gobierno, podría proceder la constitución correcta, la cual la fuerza del arte la sitúa por encima de las leyes. Y para quienes todo lo hacen gobernando con sensatez, no hay error posible, siempre y cuando tengan cuidado de la única cosa importante, que es el dispensar en toda ocasión a los ciudadanos lo que es más justo, con inteligencia y arte, y sean capaces así de salvarlos y hacerlos mejores en la medida de lo posible de lo que peor eran.

Sócrates Joven: No hay modo de rebatir lo que has dicho. $(297 a-b)$

Fijémonos en lo que se está diciendo, ya que la imagen también es precisa: la constitución correcta de una ciudad, es decir, su ordenamiento institucional, impone su fuerza, o sea, es correcta, en la medida en que descansa en el arte político y no en las leyes, que en buena disposición constitucional son jurídicamente inferiores al todo del ordenamiento jurídico. Recordemos que era con la fuerza de su alma (tês psykhês rómen, 259c) con la que el rey tenía que asumir la comprensión del gobierno. Ahora, las leyes se basan en la fuerza del arte (tes tékhnes rómen). Se sustituye a la persona por el arte que posee, aunque, acto seguido, vuelve a referirse al individuo: no hay error en los gobernantes sensatos (émphrosin) mientras observen algo importante y de magnitud: que impartan lo más justo para los ciudadanos, con el fin de salvarlos y hacerlos mejores tanto como se pueda siempre con inteligencia y arte (metà nô̂ kai tékhnes). Aquí se añade al arte el uso de la noesis, en lo cual se señala algo que es más que arte o técnica. Los gobernantes tienen que ser sensatos (émphrones), llenos de phrónesis, y entonces actuarán sin error. El gobierno sin error que se sitúa por encima de las leyes es el gobierno 
del arte político y de la inteligencia, que no es otra cosa que el arte de la phrónesis, en vistas al mejoramiento de la ciudadanía.

El texto es fundamental en otros aspectos, especialmente en la medida en que en él aparece el abecé de un problema jurídico-político fundamental: en qué se sustenta la constitución. Según el texto, la cuestión es clara: impone su fuerza del arte político que hace la constitución superior a las simples leyes. Del contenido de aquélla, el texto sólo comenta lo siguiente: todo es correcto si el gobernante es sensato, prudente e imparte justicia a los ciudadanos con conocimiento y arte, salvándolos y haciéndolos mejores de lo que eran. Queda también clara, pues, la finalidad de la constitución: proteger a los ciudadanos y hacerlos mejores en la medida de lo posible desde lo peores que eran, es decir, un asunto educativo (Monserrat 2010). ${ }^{3}$ De alguna manera, cabe recordar aquí que el conocimiento político del que se habla es siempre un conocimiento teórico (Márquez 2007, p. 52) y, por lo tanto, su ámbito de acción política es el de la persuasión (y, por ende, resultado de la educación de la ciudadanía).

Otra cuestión para tener en cuenta: el engranaje entre esta constitución superior y las simples leyes y su aplicación pasa por unos gobernantes sensatos que aprovechen con inteligencia y arte aquello más justo sin error. Frente al rechazo aristocratizante de la necesaria consideración de los muchos a convencer, el quehacer político de la ilustración queda situado como fundamento de la constitución y como pedagogía.

\section{Las imitaciones del político y el juicio de Sócrates}

Aprovechando la aquiescencia del interlocutor de considerar que los gobernantes con inteligencia y arte gobiernen con el fin de hacer mejores a los ciudadanos, el Extranjero añade esto otro que considera que no puede refutarse:

EXtranjero: Nunca una multitud, compuesta por hombres cualesquiera, sería capaz de alcanzar este saber y de administrar con inteligencia una ciudad, sino que sólo entre pocos, una cantidad mínima, si no un hombre solo, tienen que buscar aquella única constitución política, y tener las otras sólo como imitación, siguiendo lo que hasta aquí hemos dicho, de las cuales unas imitan más bien y otras más mal. $(297 b c)$

${ }^{3}$ En Gorgias 25ld, Sócrates dice que es el único que se dedica a la verdadera técnica política y a ejercitarla porque es el único que se ocupa de la mejora de sus conciudadanos. 
Se trata con este argumento de evitar una deriva que nos llevaría a conclusiones antiaristocráticas (antioligárquicas, en verdad). El sentido por donde discurre la conversación, sin embargo, es otro. Aquello formulado es una constitución inalcanzable para una multitud. Llega a ser tan difícil que sólo entre pocos o quizás en uno solamente la tomará como modelo a seguir. Las constituciones se volverán imitaciones de aquélla, y como tales, mejores o peores. El acuerdo que se suponía, ahora se pierde: el joven no entiende esto de la "imitación", a pesar de que ya se había hablado de ello con anterioridad (293e). Entonces el Extranjero hace patente otro error cometido que no es baladí. El joven, como es habitual en el diálogo, tampoco se percata de qué error se trata: "Tenemos que buscar uno [sc. error] tal del que no estamos acostumbrados, y que no es fácil de captar; sin embargo, tenemos que intentar atraparlo."

El texto es difícil de entender: quizás quiera decir que las constituciones se sostienen en la medida en que surgen las leyes escritas de la buena constitución. Pero no queda nada claro de qué forma las constituciones pueden conocer las leyes de la mejor, a no ser que se sobreentienda que las constituciones se sostienen en la medida que imitan la constitución correcta al máximo (o sea, en cuanto la conocen de alguna manera). Lo que hemos visto que es loable, aunque no necesariamente lo más correcto, es la obediencia a la ley. Llevado al extremo, se da lo que sigue:

EXTRANJERO: Esto: el hecho de que, desde la ciudad, nadie se atreve a hacer nada al margen de la ley, y el que se atreve es condenado a muerte y a todas las penas más terribles. Y esto es lo más correcto y bello, pero para ocupar un segundo lugar en el caso que lo que hemos descrito lo ponemos aparte. Ahora, como que se ha llegado a esto que hemos aceptado para el segundo lugar, ejecutémoslo hasta el final. (297e)

Es éste un momento especialmente dramático en el diálogo, pues la tensión se palpa en la escena. El lector sabe que Sócrates, el día anterior, ha ido a conocer la acusación que pesa sobre él (Teeteto $210 d)$ y está a punto de ser condenado a muerte por desobedecer las leyes de la ciudad. Quizás no sería condenado en la ciudad de la primera constitución, si es que Sócrates fuese el político-rey. Quizás tampoco lo sería en aquella ciudad donde se aceptara la reforma de las leyes con el previo convencimiento de los ciudadanos — si es que Sócrates fuera capaz de convencerlos y no tanto de ponerlos en su contra- Como no estamos en el mejor régimen, resulta que, en el orden constitucional-legal positivo, el respeto a las leyes se guarda, 
así, con las máximas penas. Si Sócrates ha desobedecido las leyes de la democrática Atenas, su sentencia es justamente legal. ${ }^{4}$

El diálogo relatado en el texto, ajeno a la situación socrática que se mantiene presente para el lector, continúa con el retorno a las "imágenes (eikónas) con las que fue forzoso comparar siempre los gobernantes reales", la del buen piloto y la del médico "que valen para muchas otras" (297e)..$^{5}$ La imagen es homérica y parece ser la primera cita poética de todo el diálogo (Rosen 1995, p. 172). No es de extrañar sin embargo el recurso a las imágenes del médico, del maestro en gimnasia, del piloto, como modelo de competencia técnica en otros diálogos platónicos (Protágoras 313d, Gorgias 464b-d, 465c, $467 c-d, 487 b$, República 406b, Leyes 916a, por ejemplo).

El Extranjero se propone considerar el siguiente diseño (skhêma). ¿Qué resulta de la tergiversación de la imagen en la práctica de la medicina y de la navegación? Los médicos tanto pueden salvar a sus pacientes como maltratarlos con incisiones, cauterizaciones y exigiéndoles el abono de unos honorarios inmensos de los cuales sólo gastan una mínima cantidad en el enfermo; del resto, se aprovechan. Cabe el caso, también, que se dejen comprar por parientes o enemigos del enfermo y lo asesinen. Los pilotos, otro tanto: pueden abandonar a los viajeros después de hacerse a la mar, o provocar un accidente o hacer naufragar la nave. Frente a estas posibilidades se decide en consejo lo siguiente: no permitir que nunca nadie domine sin control alguno estas artes, y se convocará la asamblea, o a todo el pueblo, o a los ricos sólo y, entonces, a los ciudadanos particulares y a los otros artesanos les corresponderá exponer su opinión acerca de la navegación y las enfermedades: cuándo es necesario administrar éstos o aquellos remedios o usar el instrumental médico, o bien cuándo es necesario aparejar las naves, cómo es necesario comportarse frente a los peligros de la navegación, frente a los piratas, cuándo es necesario combatir contra otras naves. La opinión de la mayoría se escribiría en tabletas piramidales o en columnas (Accatino 1997, n. 155; cfr. Aristóteles Constitución de Atenas 7, 1, y Plutarco, Vida

${ }^{4}$ Rowe (2001) no se refiere estrictamente al paralelo argumental entre este pasaje del Político y el juicio de Sócrates, y lo sitúa en un momento menos "socrático" de la reflexión platónica.

${ }^{5}$ La cita aparece entera en Banquete $214 b$, pronunciada por Alcibíades y dirigida al médico Erixímaco (Rosen 1995, pp. 171-172; "Exactamente tal como se señaló antes, es imposible presentar o exponer al gobernante real en su propia persona, porque esta persona es un mito".) Para Miller (1980, p. 96), el pasaje que va de $297 c$ a $301 a$ es "un pasaje extraordinario, la representación más intensa de ironía pedagógica en el diálogo". 
de Solón 25), o sin escribirse se convertiría en uso obligado, con lo cual todo cuidado de enfermos o toda navegación debería practicarse según estas normas. El joven encuentra absurdas (átopa) estas cosas. Encuentra, aún peor, la siguiente propuesta: que los encargados del cuidado de las enfermedades y de la navegación fueran elegidos entre la gente y se condujesen según la normativa prevista.

El Extranjero insiste aún en las consecuencias de una situación como ésta. Se crearán, comenta, unos tribunales ante los cuales quien quiera podrá acusar por no haber pilotado las naves o curado a los enfermos según las normas establecidas (o las normas de los antepasados). El joven Sócrates se escandaliza de tal situación: quien se avenga a gobernar en estas condiciones, dice, se merece estos juicios y las penas que conlleven. Sea que al joven Sócrates le resulte totalmente ajena cualquier ambición política (según la respuesta que aparece en 299a7-b1, Benardete 1984, III, p. 139) o simplemente que no se supera el prejuicio oligárquico, hasta aquí hemos visto traslucirse la figura del pensamiento político que comentábamos: una democracia que en la medida que puede ser educada deviene sostén del ejercicio político.

Los "magistrados" (árkhontes, literalmente "los gobernantes") es la palabra usual para designar a todos aquellos que ostentan cargos de gobierno y de administración. En Atenas, todos los magistrados antes de ejercer el cargo debían jurar gobernar según las leyes. Por esto se entiende que los políticos están subordinados y sirvan las leyes de la ciudad (en Leyes $715 \mathrm{~cd}$, la perspectiva resulta invertida; cfr. Accatino 1997, p. 178, n. 156).

La decisión final de quitar el poder autónomo a médicos y pilotos (cfr. 298cl) se transforma ahora en una ley que prohíbe la investigación (cfr. 299c7). Además, añade el Extranjero, se deberá establecer la ley según la cual se prohíba la investigación o especulación al margen de la norma escrita sobre navegación y medicina, con lo cual, aquel que la desobedezca será tildado de "astrólogo, charlatán y sofista" (meteorológon, adoléskhen tinà sophistén, 299b). Parecen obvias las referencias a Sócrates: de hecho, había sido acusado de lo mismo por Aristófanes (Las nubes) o lo sería inmediatamente después de la escena del Político en el juicio contra él por gente como Anitos y Meleto. ${ }^{6}$ Quizás de lo mismo que fue acusado Platón, que era tildado de sofista en la corte de Siracusa (cfr. Plutarco, Dión 14). En el

${ }^{6}$ Los epítetos "investigador de los cielos" (meteoroléskhes o meteoroskópos) y "charlatán" (adoléskhes) son comunes en Platón: cfr., por ejemplo, Cratilo 401b, Fedro $270 a$, y, sobre todo, República $488 d-489 a$. 
texto del Político aún se resalta más: se permitiría que cualquiera lo denunciase y lo hiciera comparecer ante un tribunal alegando que es un corruptor de los más jóvenes por haberlos convencido de no regirse según las leyes acerca de la navegación o la medicina. Si fuera probada la acusación debería castigársele con las penas más severas. Se nos presenta, por lo tanto, doblemente, el juicio de Sócrates y el problema que Sócrates plantea a Teodoro al inicio de la jornada: cuáles son las apariciones del filósofo en la ciudad, o reformulándolo, a la par que degradando la pregunta, cómo se diferencian filósofo, político y sofista (Sofista $216 c d$ ). El texto continúa con su cruda ironía:

Extranjero: [...] Efectivamente, no puede haber nada más sabio que las leyes. Todo el mundo puede aprender el arte de la medicina y de la sanidad, el arte de pilotar y la náutica, puesto que es posible a quien quiera asimilar los escritos y las normas paternas instituidas. Si acerca de estos saberes, las cosas fueran tal y como decimos, Sócrates, en lo referente al arte militar y a cualquier tipo de cacería en su conjunto, o el dibujo - da igual en cual de sus partes - del arte imitativo en general, o hasta del arte de la carpintería, o de cualquier arte mobiliario colectivo, o de los campesinos, o todo arte relativo a las plantas, o, aún, si viéramos que se rige por normas escritas en el arte de la remonta de caballos o de criar cualquier otro rebaño, o de la adivinación o en todo lo que abarca el arte de servir o el juego de damas o toda la aritmética, pura o aplicada al plano, al sólido o al movimiento, en lo referente a todos los actos de este tipo, ¿qué se seguiría si todos se practicasen según un código escrito y no según un arte?

Sócrates Joven: Es evidente que se perderían del todo las artes y que en el futuro ya no se darían más, por culpa de esta ley que prohíbe investigar, de manera que la vida, que ahora ya es terrible, en un tiempo futuro se volvería absolutamente imposible de vivirla. (299ce)

El sentido es evidentemente irónico. ${ }^{7}$ Es, primero, un momento paralelo al de la justa medida, ya que sin ella tampoco existirían las artes (284a). En segundo lugar, las referencias a la figura de Sócrates son evidentes (Hirsch 1995, pp. 184-189). En tercer lugar, la respuesta del joven sorprende por su claridad, rigor, extensión y convicción. Un cuarto aspecto se refiere a los ámbitos del saber que se exponen.

i) El paralelo de la justa medida. Notemos también que éste es un momento importante en la estructura de los nudos internos que

${ }^{7}$ Lo mismo aparece en Protágoras $319 b-d$ cuando habla Sócrates: los atenienses, dice, reunidos en asamblea piden consejo a los técnicos sobre muchas cuestiones; pero cuando se trata de cuestiones políticas, cualquiera se atreve a decir lo que le parece. 
sustentan el diálogo. Estamos asistiendo a un momento paralelo al que se producía en la introducción de la noción de justa medida y su relación con el arte de la política. Anteriormente, hacia el centro del diálogo, se convenía que, sin la justa medida, el arte o técnica no es posible $(284 a)$. Ahora vemos que tampoco es posible el arte y el conocimiento sin la investigación, el examen, la búsqueda y el cuestionamiento crítico. No permitir el cambio en las leyes es no atender a las variaciones en las circunstancias que han obligado a establecer la ley y no atender a la perfectibilidad de todo lo humano. Además, en el momento en que se prohíbe el examen, el camino que queda es el de la involución, el de la decadencia, el de convertir la vida en algo del todo tedioso. La referencia que aquí se nos presenta más claramente es a los diferentes momentos de la vida tal como se consideraban en el mito explicado anteriormente: abandonado a sí mismo, el universo ve su orden amenazado por el olvido del saber, por la pérdida de memoria. La escritura es el remedio de la memoria y a la vez su veneno. ${ }^{8}$

ii) Las referencias a Sócrates. Tal y como acabamos de ver, se retratan aspectos conocidos de vida socrática: su voluntad de escudriñar los saberes aparentes de la ciudad, ya sea el de los sabios, el de los políticos, el de los artesanos. Es quizás éste uno de los momentos del diálogo en que el silencio de Sócrates en escena es más notable. La escena es un paralelo de su juicio o, cuando menos, las acusaciones contra Sócrates se hacen presentes, las cuales se suponen conocidas, puesto que el día anterior había acudido al Pórtico del Rey para saber de la acusación que pesaba contra él, como se lee en el final del Teeteto. ¿Por qué no hay entonces una defensa de Sócrates frente a la acusación? ¿La situación es tal y como la enmarca el Extranjero y, por tanto, no hay remedio, en el sentido de que la aparición en la ciudad de eso que pueda ser el filósofo es inevitablemente problemática? Nos encontramos, por un lado y en sentido extradialogal, que se hace necesario acudir irremisiblemente a la Apología de Sócrates platónica. Por otro lado, empero, sí que hay en cierto modo una defensa frente a la acusación, que es lo que consideraremos acto seguido.

iii) La respuesta del joven Sócrates. Asistimos a la intervención más larga que pronuncia el joven discípulo de Teodoro. Lo que en ella se dice resulta claro: sin un libre examen no hay la posibilidad de

${ }^{8}$ Para Rosen, el Extranjero habla aquí como si la decadencia se debiera a la falta de conocimiento técnico, y ello es propiamente una tesis de la ilustración científica mientras que Aristóteles, en cambio, proporcionaría una doctrina más adecuada que el análisis propuesto por el Extranjero, a saber, la necesidad de habituar la ciudadanía en la virtud (Rosen 1995, pp. 131, 173; sobre Aristóteles, Políticos, I, 1257b25 ss.). 
mantener el esfuerzo de las artes para aliviar la vida de sus aspectos más horribles. Una respuesta así ciertamente es una buena respuesta en el zenit de la dramática del diálogo. Mitchell Miller comenta que "con esta cuestión alcanzamos un momento de clímax en el juego dramático del diálogo. Dirigiéndosele por el nombre, el Extranjero pregunta al joven que juzga, de hecho, entre el viejo Sócrates y sus jueces" (Miller 1980, p. 99). La respuesta del joven mantiene un parecido con lo que dirá después Sócrates en su defensa frente al tribunal de la ciudad: anexétastos bíos ou biotòs anthrópo ("una vida sin examen no es una vida humana", Ap. 38a). Los dos Sócrates ahora se asemejan más que sólo por el nombre. Ya Paul Friedländer reconocía la importancia de este momento añadiendo, además, que el destino de Sócrates simboliza el inevitable conflicto entre las leyes de la ciudad y aquel hombre cuya existencia representa el conocimiento del político real actuando sin ayuda de leyes (Friedländer 1960, III, p. 277).

iv) En lo referente a los ámbitos del saber que el Extranjero expone, Seth Benardete (1984, p. 137) ha anotado un paralelo que constituye una de las tantísimas sorpresas que esconde el texto platónico cuando se lo somete a una lectura esmerada y que hace extremadamente atrevido afirmar que el arte platónico pueda decaer en determinados momentos. A simple vista advertimos que se mezclan muchos de los momentos anteriores de la conversación (la justa medida, el mito), pero además, su número de siete nos puede llevar a sospechar el siguiente paralelo con los siete tipos de regímenes: el arte militar y cualquier tipo de cacería en general corresponderían a la tiranía (Sofista 222c); el dibujo, o arte imitativo en general, comenta que florece especialmente en la oligarquía; el arte de la carpintería, o de cualquier artesanía corresponde a la democracia urbana que se identifica con la democracia sin leyes; el campesinado, o todo arte relativo a las plantas, correspondería a la democracia legal, que tendría un sustrato social eminentemente agrario; la remonta de caballos, o criar cualquier otro rebaño, correspondería a la aristocracia de los caballeros; la adivinación o todo lo que abarca el arte de servir correspondería a la monarquía del rey-sacerdote; y, finalmente, el juego de damas o toda la aritmética correspondería al régimen correcto, al régimen de quien sustenta el conocimiento. Es notable que esta lista de saberes se presente doblada, ocupando el primer término un arte más concreto que el segundo, que es más general. De hecho, la semejanza con los resultados de la diéresis bifurcatoria es clara. Aún más, cada doblete desempeña un papel con otros momentos del diálogo. El arte militar es visto como una especie de cacería, y 
la empresa que se llevan entre el Extranjero y el joven Sócrates se interpreta a menudo como una cacería del político (236bl-2, 264a5, 285d9, 290d5, 29lc6. Cfr. Eutidemo 290bc). El dibujo y el arte imitativo en general se refieren al momento en que el mito es comparado, primero, con una estatua recargada y después con una pintura inacabada. El término tekhtonikés se refiere tanto al arte de la carpintería como al de la arquitectura. La carpintería, parte del arte mobiliario colectivo, proporciona las naves de la navegación y las herramientas de la industria de la tejeduría; la arquitectura es el ejemplo recurrente de las primeras diéresis del diálogo. El campesinado, dentro del arte relativo a las plantas, debería cuidar en cierto modo de los "hombres nacidos de la tierra". La remonta de caballos es el caso concreto de la crianza de rebaños: precisamente se habían referido al político como el pastor de los rebaños humanos. La adivinación es el caso concreto del arte de servir: era entre los servidores de la ciudad que se escogía el adivino (290c). Finalmente, el juego de damas como caso particular de la aritmética: el juego de damas se había citado anteriormente como caso de un saber que, como el del político, era poseído por unos pocos en la ciudad. Lo que es más importante es que ahora este saber del juego se vea como un caso concreto de la aritmética. Ésta, a diferencia de todas las demás ejemplificadas, se despliega en una exposición de su contenido: aritmética pura o aplicada al plano, al sólido o al movimiento. Es un hecho que el Extranjero se encuentra entre matemáticos, Teodoro y sus discípulos, y no sería extraño que esta expansión fuese una complicidad con su interlocutor, un joven aprendiz de matemáticas. Cabe quizás recordar que la aritmética pura o aplicada al plano, al sólido y al movimiento corresponde en República 284e al aprendizaje propedéutico de la filosofía y de la política filosófica.

\section{La segunda navegación: de los legisladores a la doble} fundamentación de la ley

El Extranjero continúa con el esquema o diseño. Aún sería peor, dice, si en este estado de cosas donde gobiernan según las leyes sucediera que alguien gobernase escogido a mano alzada o por la suerte e intentara con una total ignorancia tratar las cosas al margen de las leyes por ganancia o capricho (e kháritos). El joven reconoce en eso una gran verdad. Resulta que aquí estaba el error que el Extranjero había visto y que le ha llevado a recorrer todo este rodeo $(297 b-300 c)$. Este pasaje se entiende, a veces, como una revalorización de la ley respecto a las críticas que ha recibido anteriormente (Skemp 1957, 
ad. loc.). De hecho, se vuelve a asumir irónicamente lo que se había explicitado antes, que se podían establecer leyes y que la situación aún puede ser peor que el gobierno de las leyes.

Extranjero: Porque, creo, que aquel que actúa al margen de las leyes que se basan en una larga experiencia, en las cuales algunos asesores siempre han aconsejado apropiadamente (khariéntos) y han persuadido al pueblo que las consolide así, aquel, digo, que se atreve a actuar contra ellas, en lugar de un error, comete un error mucho mayor y tergiversará nuestra obra más duramente que las prescripciones mismas (tôn suggrammáton).

Sócrates Joven: ¿Cómo no sería así? (300b)

Fijémonos en el texto donde queda establecida la primera imitación de la constitución correcta: unas leyes, basadas en la experiencia, con consejos de expertos, que enseñen al pueblo a consolidarlas o a promulgarlas (thésthai). El esquema que se dibuja propone claramente una doble fundamentación de la ley (legislador-[experiencia]-leypueblo). La larga experiencia (ek peíras pollês) en la que se basan las leyes nos indica que la fundamentación de esta legislación es inferior a la que proporcionaría el saber, e inferior también al conocimiento técnico (cfr. Gorgias 462b ss.; Rowe 1995a, p. 230, nota a 300b1-6; Accatino 1997, p. 179, n. 160). Pero en este caso las leyes reciben en este momento una doble fundamentación: la de la experiencia y la del consentimiento del pueblo. La situación es claramente tensa.

EXTranjero: Por eso, para los que promulguen leyes y normas (syngrámmata) acerca de lo que sea, hay una segunda navegación: no permitir nunca que ningún único hombre ni la multitud hagan jamás nada al margen de esto. $(300 c)$

Peor que malas leyes sería la situación en la que el gobernante actuase al margen de la ley escrita por beneficio propio o por capricho. El joven Sócrates reconoce que esta afirmación del Extranjero es una gran verdad. En este momento del diálogo se procede a una revaloración de las leyes después de haberlas sometido a crítica explícita por su inadecuación ante los problemas de la realidad. Se establece claramente que la primera imitación de la constitución correcta sería aquel régimen sostenido por unas leyes basadas en la experiencia a través del consejo de los expertos que enseñan al pueblo a promulgarlas y sostenerlas. En este momento todos los elementos quedan 
establecidos claramente. Se necesita, empero, un expediente accesorio, la segunda navegación.

La segunda navegación ${ }^{9}$ del Político de Platón resulta ser la prohibición de desobedecer las leyes. No obstante, esta restricción se aplica a los individuos particulares y a la multitud (méte héna méte plêthos). ¿Entre estos dos extremos, no quedaría la posibilidad no considerada de una intervención política en el momento oportuno por parte de aquellos que han dedicado el ocio en la amistad a la observación de la ciudad y a la búsqueda de la verdad, como sugiere la Carta VII?

$\mathrm{El}$ joven Sócrates encuentra adecuada tal prohibición. Ahora bien, el Extranjero, que en esta última respuesta puede haber sido ambiguo, en el sentido de promover leyes reverenciables en exceso, procurará seguidamente sacar al joven Sócrates de su excesiva sumisión a la legalidad. El problema fundamental es garantizar a la vez la fortaleza y la perfectibilidad de la "constitución".

Las leyes y las costumbres diseñadas por los entendidos (o expertos) son imitaciones de la verdad. El verdadero político, se reitera, hacía muchas cosas según su arte, sin estar preocupado por las normas escritas, siempre que tuviera opiniones superiores a las que él mismo había redactado y enviadas a algunos que estaban lejos o ausentes (como Solón, sugiere Rowe 1995a, p. 231). En cambio, aquellos muchos que, teniendo leyes vigentes, las varían pensando que es preferible, actúan, dentro de sus posibilidades, como el legislador auténtico, pero si no tienen ciencia, la imitación sería pésima; y, si son técnicos expertos, resulta que no sería una imitación sino el caso auténtico. La posibilidad legislativa que se nos ofrece resulta estar difícilmente en el medio virtuoso posible entre la multitud informe y el uno divino como acción política oportuna y prudente.

Como todavía permanece el acuerdo según el cual la multitud es incapaz de adquirir una técnica o arte (vid. 293a2-4 y 297b7$c 2$.$) , el diálogo acuerda que, si existe un arte real, no lo detentará$ ni la multitud de ricos ni el conjunto del pueblo, incapaces del saber político. Ante esta dificultad, las ciudades, para imitar a la auténtica, deben abstenerse de hacer nada contra las leyes escritas o las normas paternas, si es que están vigentes. ${ }^{10}$ Para un régimen históricamente existente, imitar la única constitución verdadera es

\footnotetext{
${ }^{9}$ La segunda navegación es un tema recurrente en Platón: Fedón 99c, Filebo 19c, Leyes $875 d$ y Carta VII 337 c.

${ }^{10}$ Miller (1980) cree que 300e-301a es un caso de ironia pedagógica; en Critón, donde se defiende la obediencia a las leyes, es un caso de ironía terapéutica, pues Critón no estaría en disposición de aprender.
} 
respetar las leyes dadas: un caso claro de conservadurismo. Sócrates joven da en este caso un asentimiento entusiasta, respuesta que ha permitido a ciertos intérpretes pensar en una conversión del joven al "constitucionalismo" (Gill 1995, pp. 292-305).

El argumento sería del todo válido si la acción política estuviese copada exclusivamente por la unidad y la multiplicidad. De otra posibilidad el texto no hace mención, sino que se pasa a considerar el nombre que reciben los regímenes según gobiernen respetando o no las leyes. Si gobiernan los ricos (hoy ploúsioi - el texto no dice los pocos- $),{ }^{11}$ y si se cumple la condición que acabamos de explicitar, o sea, imitando las leyes, se llama aristocracia, si no oligarquía. Si gobierna un hombre según las leyes, se denomina rey. Con el nombre de rey (basileús) no se distingue entre quien gobierna según las leyes por saber o quien por opinión (República, $476 d$ ss.). Rey lo es tanto el verdadero político como el monarca que gobierna según las leyes. Cómo había dicho el Extranjero, ahora no hacemos uso de distinciones en el lenguaje, pero es evidente que la identificación es errónea. El primero tiene saber y el segundo sólo opinión. ${ }^{12} \mathrm{La}$ frase siguiente, pese a que el texto griego no presenta variaciones, ha sido cambiada por Diès (1935, p. 75, n. 1) y algunos otros editores que lo siguen (Rowe 1995a, Accatino 1997, Balasch 1997; la discute Skemp 1957, p. 211). Según el texto griego sin modificar, la traducción sería: "Por esto", dice el Extranjero, "los cinco nombres de las constituciones ahora mencionadas se resuelven en uno solo" (301b). El sentido es el siguiente: el Extranjero saca una conclusión brusca de la afirmación pronunciada anteriormente en 293c5-7, según la cual la constitución correcta es la única constitución. Si la única constitución es un reino, entonces de los cinco nombres acostumbrados sólo sería necesario uno. El resultado es una lista de cinco nombres: tirano, rey, oligarquía, aristocracia y democracia. Los dos primeros, que son las dos posibilidades de gobierno de uno solo, corresponden a los gobernantes, los tres últimos a formas de gobierno. Ahora bien, el Extranjero reserva en esta intervención el nombre de la monarquía a aquella forma anterior que hemos dejado de lado porque los hombres desconfían de que alguien pueda merecer aquel gobierno que

${ }^{11}$ Cfr. con 298e "escoger entre ricos y el pueblo", y con $292 d$ : "el gobierno de unos pocos".

${ }^{12}$ Cfr. Teeteto $201 a c$, la opinión correcta se obtiene a partir de lo que dicen aquellos que poseen ciencia. Vid. Cambiano (1971, pp. 133-136). En Banquete $202 a$, la opinión correcta es el medio entre la ciencia y la ignorancia y, a diferencia de la ciencia, no sabe dar razón de sí. En Menón 97a ss., la opinión cierta puede asegurar la corrección de la acción. 
el saber proporciona y que permitiría la distribución correcta de lo que es justo y piadoso. Más bien se piensa que quien poseyera este poder sin someterse a las leyes asesinaría, maltrataría y perjudicaría, es decir, sería un tirano. Ahora bien, pasa también que si gobierna uno solo al margen de las leyes y de las costumbres, y finge ${ }^{13}$ hacer lo mejor, como el experto necesario al margen de lo escrito, aquello que realmente será una guía será una pasión y un desconocimiento de aquello que debe imitarse, y entonces recibe el nombre de tirano $(c f r$. República 572e ss.). Aquel que parece ser un político que supera la ley resultará ser, basado en la ignorancia y el error, la distorsión más extremada de la buena política. El caso descrito antes, empero, resultaría el de aquel que pilotara (diakubernônta) felizmente la nave del único régimen correcto.

El joven está de acuerdo. No obstante, el Extranjero añade que en las ciudades no hay ningún rey así, tal y como crece en los enjambres de abejas, en los cuales la reina se distingue de las otras en cuerpo y alma. ${ }^{14}$ Fijémonos que se está reiterando el esquema que quería corregir el mito anterior relatado en el diálogo: el pastor de pueblos semejante a un dios, diferente por naturaleza de los animales del rebaño. Como que esto, que pueda existir este ser excepcional, no puede ser, entonces — sigue el Extranjero - es necesario "reunirse para redactar escritos y retomar por aquí las pistas de la constitución más verdadera" (30le). El joven responde que "probablemente". No parece estar tan seguro como antes. Quizás porque se reitera claramente la imposibilidad del primer modelo.

El Extranjero vuelve a dirigirse a su interlocutor por el nombre en la conclusión de este fragmento, y encuentra entonces que no son de extrañar las desgracias que ocurren a los regímenes políticos que siguen las normas escritas y las costumbres, pero que no actúan (práxeis) siguiendo un saber (epistéme). Se reitera, pues, la necesidad de un fundamento constitucional más allá de la letra de texto, la necesidad de un arte de ajustes, sobre el cual debe fundamentarse el arte político, porque si no el resultado es destructivo. Lo admirable resulta ser la resistencia que la ciudad ofrece de natural (phýsei), pues las ciudades actualmente se encuentran en la circunstancia peor

${ }^{13}$ Homenaje de la tiranía al buen gobierno.

${ }^{14}$ El enjambre de abejas era un ejemplo utilizado en $293 d$, precisamente sobre constituciones de las ciudades. Cfr. Aristóteles, Política, VII, 14.1332b. De las abejas como ejemplo de la educación de los filósofos: República 489e ss.; cfr. $492 a$. Jenofonte dice de Ciro que es un rey por naturaleza, como la reina lo es de las abejas (Ciropédia 5.1.24). En Leyes 694c, Ciro no lo sería porque no era educado (Sales y Monserrat 2009). 
y resisten sin hundirse o arruinarse durante bastante tiempo a pesar de los gobernantes. Ahora bien, esto no es una objeción a la desgracia de un mal fundamento político porque, como continúa el Extranjero, muchas ciudades "se han perdido como naves hundidas, y han desaparecido, y aún se perderán más por la maldad de los pilotos y de los tripulantes, que han chocado con la más gran ignorancia con respecto a las cosas de la máxima importancia: no saben nada de política, y se creen que precisamente es este saber el que dominan más entre todos los saberes" (302ab).

El joven asiente diciendo que esto es una gran verdad (alethésta$t a$ ). Con este acuerdo se acaba esta sección, pues, acto seguido, el diálogo se desborda (302c5), y también se acaba la reiterada imagen de la nave, metáfora del gobierno de la ciudad y de la ciudad misma, pero con unos leves añadidos, que no dejan de ser importantes. Si inicialmente la responsabilidad de la nave correspondía a su piloto, ahora se habla "de la maldad de los pilotos y tripulantes" (kubernetôn kai nautôn mokhtherían, 302a7) como la responsable del hundimiento y la desaparición. La razón es bien clara: éstos no son el piloto originario (ni como el dios que abandona el universo al mar de la desemejanza), que conoce lo que es necesario, sino que son máximamente ignorantes de las cosas más grandes, aquéllas normalmente objeto de estudio de la filosofía. No saben de política y se piensan que saben de lo que no saben. Nótese cómo la responsabilidad es compartida. En toda esta parte del texto corresponde a la ciudad la aceptación del gobernante. La ciudadanía tiene un papel ineludible que debe ser pensado.

La nave de la ciudad está en manos de quien está. Con "esta evidencia", el Extranjero pasará a tratar del mal menor: cuál de las constituciones incorrecta es la menos mala para vivir. El texto indica que entramos en medio de una riada que desbordará los márgenes de la argumentación como un río que inunda cuando sale de su cauce (Monserrat 1999, pp. 226-233). Sin duda, en este mundo de imperfección, la constitución de lejos menos mala es la democracia (Koyré 1962, p. 157), y la posibilidad de un decrecimiento de su carácter defectuoso resulta directamente proporcional a la posibilidad de que la tarea educativa y los procesos de conocimiento compartido sean efectivos en el momento de sostener por parte del demos la instauración de la legalidad.

La imagen náutica que domina este pasaje nos recuerda su lugar simétrico en la primera mitad del diálogo, la imagen que aparecía en el mito del dios que dirigía el universo como un timonel dirige su 
nave (272e). En nuestra era, es decir, aquella era en la que los hombres sólo contamos con nosotros, pues los dioses han abandonado el mundo (utilizando el lenguaje del mito), ¿qué sentido tiene considerar la política como si estuviéramos embarcados en una nave, la ciudad? No resulta claro y siempre es cuestión debatida considerar qué nos ha conducido hasta aquí, hacia dónde va y quién debe gobernarla. ${ }^{15}$

\section{BIBLIOGRAFÍA}

Abad, A. y J. Monserrat, 2009, "Habermas and Ackerman, a Synthesis of Their Thought Applied to the Legitimation and Codification of Legal Norms", Ratio Juris, vol. 23, no. 4, pp. 510-521.

Accatino, P., 1997, Platone. Politico, Laterza, Bari.

Balasch, M., 1997, Plató. Diàlegs, vol. 16, El polític, Fundació Bernat Metge, Barcelona.

Benardete, S., 1984, The Being of Beautiful. Plato's Theaetetus, Sophist and Statesman, The University of Chicago Press, Chicago.

Briguglia, A., 2006, Il corpo vivente dello Stato. Una metafora politica, Bruno Mondadori, Milán.

Cambiano, G., 1971, Platone e le techniche, Einaudi, Turín.

Castoriadis, C., 2003, Sobre el Político de Platón, trad. Horacio Pons, Fondo de Cultura Económica, México.

Diès, A., 1935, Platon. Oeuvres Complètes, IX/1, Le politique, Les Belles Lettres, París.

Friedländer, P., 1960, Platon III. Die platonischen Schriften Zweitte un Dritte Periode, W. de Gruyter, Berlín.

Garrigasait, R., 2009, Plató. Cartes, Fundació Bernat Metge, Barcelona.

Gill, C., 1995, "Rethinking Constitutionalism in Statesman 291-303", en Rowe 1995b, pp. 291-333.

Hansen, M.H., 1991, The Athenian Democracy in the Age of Demosthenes, Blackwell, Oxford/Cambridge, Mass.

Hirsch, U., 1995, "Mimeisthai und verwandte Ausdrücke in Platons Politikos", en Rowe 1995b, pp. 184-189.

Hutchins, E., 1995, Cognition in the Wild, MIT Press, Cambridge, Mass.

Ibáñez-Puig, X., 2011, "El tribunal de justicia como figura del saber en el Teeteto de Platón", en F. Lisi, M. Migliori, J. Monserrat, Formal Structures in Plato's Dialogues. Theaetetus, Sophist and Statesman, Akademia Verlag, Sankt Agustin, pp. 136-147.

${ }^{15}$ Este texto se escribió en el marco del proyecto Grup de Recerca 2009SGR447 "Eidos: Hermenèutica, Platonisme i Modernitat", Universitat de Barcelona. Proyecto de Investigación financiado por la Dirección General de Investigación del Ministerio de Educación y Ciencia HUM2007-62763/FISO. (Agradezco a los revisores anónimos del artículo las sugerencias y discusiones aportadas que he procurado tener en cuenta.) 
Ibáñez-Puig, X., 2007, Lectura del Teetet de Plató. Saviesa i prudència en el Tribunal del Saber, Barcelonesa d'Edicions, Barcelona.

Koyré, A., 1962, Introduction à la lecture de Platon, Gallimard, París.

Márquez, X., 2007, "Theory and Practice in Plato's Statesman", Ancient Philosophy, vol. 27, no. 1, pp. 31-53.

Mas, S., 2009, "La crítica de Platón a la democracia: paideía politikê", en L. Sancho Rocher (coord.), Filosofía y democracia en la Grecia Antigua, Prensas Universitarias de Zaragoza, Zaragoza, 2009, pp. 162-198.

Miller, M., 1980, The Philosopher in Plato's Statesman, Martinus Nijhoff, La Haya [reeditado en 2004, por Parmenides Publications, Las Vegas].

Monserrat, J., 2010, “Avaluació-tècnica i Educació-eròtica en El polític de Plató (306a-31lc)", Temps d'Educació, no. 37, pp. 510-531.

d'Edicions, Barcelona.

Rosen, S., 1995, Plato's Statesman. The Web of Politics, Yale University Press, New Haven/Londres.

Rowe, C.J., 2001, "Killing Socrates: Plato's Later Thoughts on Democracy", Journal of Hellenic Studies, vol. 121, pp. 63-75.

—-, 1995a, Plato. Statesman, Aris and Philips, Warminster.

- (comp.), 1995b, Reading the Statesman. Proceedings of the Symposium Platonicum III, Akademia Verlag, Sankt Agustin.

Sales, J. y J. Monserrat, 2009, "A More Political Animal Than Bees: Polity as an Intermediate state, as the Highest State, or as an Agent of Stability", Studia Neoaristotelica, vol. 6, no. 1, pp. 3-14.

Saxonhouse, A., 2006, Free Speech and Democracy in Ancient Athens, Cambridge University Press, Cambridge.

Schofield, M., 2006, Plato: Political Philosophy, Oxford University Press, Oxford.

Skemp, J.B., 1957, Plato. Statesman, Bristol Classical Press, New Haven Bristol.

Recibido el 9 de diciembre de 2010; revisado el 16 de mayo de 2011; aceptado el 13 de septiembre de 2011. 